\title{
Synergistic Antifungal Activity of Chito-Oligosaccharides and Commercial Antifungals on Biofilms of Clinical Candida Isolates
}

\author{
Monica Ganan ${ }^{1,2} \mathbb{D}$, Silje B. Lorentzen ${ }^{1}$, Peter Gaustad ${ }^{2}$ and Morten Sørlie ${ }^{1, * \mathbb{D}}$ \\ 1 Department of Chemistry, Biotechnology, and Food Science, Norwegian University of Life Sciences (NMBU), \\ 1432 Aas, Norway; monicaganan@gmail.com (M.G.); Silje.lorentzen@nmbu.no (S.B.L.) \\ 2 Department of Microbiology, Institute of Clinical Medicine, University of Oslo and Fürst Medical Laboratory, \\ 0154 Oslo, Norway; peter.gaustad@medisin.uio.no \\ * Correspondence: morten.sorlie@nmbu.no
}

Citation: Ganan, M.; Lorentzen, S.B.; Gaustad, P.; Sørlie, M. Synergistic Antifungal Activity of ChitoOligosaccharides and Commercial Antifungals on Biofilms of Clinical Candida Isolates. J. Fungi 2021, 7, 718. https://doi.org/10.3390/jof7090718

Academic Editor: Patrick Schwarz

Received: 12 July 2021

Accepted: 27 August 2021

Published: 1 September 2021

Publisher's Note: MDPI stays neutral with regard to jurisdictional claims in published maps and institutional affiliations.

Copyright: (C) 2021 by the authors. Licensee MDPI, Basel, Switzerland. This article is an open access article distributed under the terms and conditions of the Creative Commons Attribution (CC BY) license (https:// creativecommons.org/licenses/by/ $4.0 /)$.

\begin{abstract}
The development of yeast biofilms is a major problem due to their increased antifungal resistance, which leads to persistent infections with severe clinical implications. The high antifungal activity of well-characterized chitosan polymers makes them potential alternatives for treating yeast biofilms. The activity of a chito-oligosaccharide with a depolymerization degree ( $\mathrm{DP}_{\mathrm{n}}$ ) of 32 (C32) and a fraction of acetylation $\left(\mathrm{F}_{\mathrm{A}}\right)$ of 0.15 on Candida sp. biofilms was studied. The results showed a concentration-dependent reduction in the number of viable cells present in C. albicans, C. glabrata, and C. guillermondii preformed biofilms in the presence of C32, especially on intermediate and mature biofilms. A significant decrease in the metabolic activity of yeast biofilms treated with C32 was also observed. The antifungals fluconazole (Flu) and miconazole (Mcz) decreased the number of viable cells in preformed early biofilms, but not in the intermediate or mature biofilms. Contrary to Flu or Mcz, C32 also reduced the formation of new biofilms. Interestingly, a synergistic effect on yeast biofilm was observed when C32 and Flu/Mcz were used in combination. C32 has the potential to become an alternative therapeutic agent against Candida biofilms alone or in combination with antifungal drugs and this will reduce the use of antifungals and decrease antifungal resistance.
\end{abstract}

Keywords: chito-oligosaccharides; chitosan; antifungal; yeast; Candida; biofilm

\section{Introduction}

Modern medicine is challenged by an increasing resistance in Candida spp to antifungals [1]. There is a need for new treatment options to overcome the problem and the development of new antifungals as well as the use of combination therapy. Chitosan as well as oligomers of chitosan known as chito-oligosaccharides (CHOS) have an antifungal effect in in vitro experiments [2].

In vitro studies have also shown that there is a synergistic, antifungal effect of the combination of commercial antifungals (CA) and chitosan as well of the oligomers CHOS [3,4]. The use of CHOS and in synergistic combination with CA will, if used for treatments of fungal infections in the future, reduce the number of antifungals needed for treatment, decrease the development of antifungal resistance, and improve the treatment of resistant fungi.

A biofilm is a microbial community and a protected niche for microorganisms. Many fungi are capable of biofilm growth. The significance of this growth is that biofilm formation can occur during many kinds of infections, and biofilm growth is a major cause of recurrent infections. Biofilms have limited drug susceptibility, making infections difficult to treat. Biofilm formation proceeds through three distinct developmental phases: early, intermediate, and mature. During these phases, yeasts progress from adherent blastospores to well-defined cellular communities encased in a polysaccharide matrix [5].

The development of pathogenic biofilms remains a major problem with severe clinical implications. Candida spp. are pathogenic and can cause both superficial and serious 
systemic disease. Many Candida systemic infections involve the formation of biofilms on implanted devices such as indwelling catheters, joint replacements, or prosthetic heart valves [6,7]. Additionally, Candida biofilms have also been related to topical infections such as vaginal candidiasis [8,9] and oral candidiasis [10]. Candida biofilms are resistant to a range of antifungal agents currently in clinical use including amphotericin B, nystatin, and azoles including the newer triazoles, and have reduced antifungal activity of lipid formulations of amphotericin B and echinocandins. Multiple resistance mechanisms are involved [11].

Chitosan is a cationic linear copolymer composed of a variable number of $\beta-(1-4)$ linked units of 2-acetamide-2-deoxy- $\beta$-d-glucopyranose (GlcNAc) and 2-amino-2-deoxy$\beta$-d-glycopyranose (GlcN) [12], obtained by the alkaline deacetylation of chitin. Properties such as the fraction of acetylation $\left(\mathrm{F}_{\mathrm{A}}\right)$, and the degree of polymerization (DP) are fundamental for the physical-chemical properties of the chitosan polymer including solubility and conformation [13-15]. The use of oligomers of chitosan, also known as chito-oligosaccharides (CHOS), allows for conquering the reduced solubility of chitosan in water at $\mathrm{pH} 7$.

The singular properties of chitosan and its polymers make them well-suited for a wide range of biomedical applications such as drug delivery [16-18], immunoprophylaxis, wound healing, neural stem cell growth, tissue engineering, and gene therapy [19]. These properties include biodegradability in the human body and low cytotoxicity, which confer chitosan good biocompatibility characteristics [20].

However, possibly one of the most interesting features of the chitosan polymer $\mathrm{CHOS}$ is its antimicrobial and antifungal activity against a wide range of bacteria, yeasts, and molds $[2,21]$. Antimicrobial activity is also known from a variety of peptides and their synergy with antimicrobial agents have been studied [22,23]. Nevertheless, the effects of CHOS and antimicrobial peptides on biofilms remain understudied and the few studies published are not quantitative. The aim of this preliminary work was to quantitatively study the effect of a well-characterized CHOS alone and in combination with commercial antifungals on Candida biofilms of clinical isolates to explore its potential to be used in antifungal therapy and for the prevention and treatment of fungal biofilms on indwelling medical devices and superficial infections.

\section{Materials and Methods}

\subsection{Enzymatic Production of Chito-Oligosaccharides}

CHOS with $\mathrm{DP}_{\mathrm{n}}$ of 32 and $F_{\mathrm{A}}$ of 0.15 as determined by ${ }^{1} \mathrm{H}-\mathrm{NMR}$ (abbreviated C32) was prepared as described previously [4,24]. Briefly, chitosan (KitoNor, Norwegian Chitosan, Gardermoen, Norway, FA 0.15, DPn 206) was obtained from Norwegian Chitosan, Gardermoen, Norway. Chitosan $\left(10 \mathrm{mg} \mathrm{mL}^{-1}\right)$ in $0.04 \mathrm{M} \mathrm{NaAc}, 0.1 \mathrm{M} \mathrm{NaCl}, 1 \% \mathrm{HCl}$ was incubated at $37^{\circ} \mathrm{C}$ and $225 \mathrm{rpm}$ until the chitosan was dissolved (approximately $15 \mathrm{~min}$ ). The $\mathrm{pH}$ was then adjusted to 5.5 with $0.5 \mathrm{M} \mathrm{NaOH}$. Chitosanase ScCsn46A $(0.5 \mu \mathrm{g}$ per mg chitosan) from Streptomyces coelicolor (UniProt accession code q9rj88) was added to the solution and the mixture was incubated for $20 \mathrm{~min}$ at $37^{\circ} \mathrm{C}$ and $225 \mathrm{rpm}$. The enzymatic reaction was stopped by decreasing the $\mathrm{pH}$ to 2.5 with $\mathrm{HCl}(0.5 \mathrm{M})$, followed by immersing the tube in boiling water for at least $10 \mathrm{~min}$ to inactivate the enzymes permanently. The resulting CHOS sample was dialyzed against $\mathrm{dH}_{2} \mathrm{O}$ for $48 \mathrm{~h}$ (water was changed every $12 \mathrm{~h}$ ) using a cellulose membrane (Float-A-Lyzer MWCO $500 \mathrm{Da}$, from Spectrum Labs, Arlington, TX, USA) to remove buffer salts from the sample. Dialyzed samples were sterile filtrated through Filtropur S $0.2 \mu \mathrm{m}$ sterile filters (Sarstedt, Nümbrecht, Germany), lyophilized, and stored at $4{ }^{\circ} \mathrm{C}$.

\subsection{Commercial Antifungals ( $C A$ )}

The triazole fluconazole (Flu) and azole miconazole (Mcz) were purchased from Sigma (St. Louis, MO, USA). Mcz is mainly used in the local treatment of superficial fungal infections while Flu can be used for superficial and deep infections. 


\subsection{Candida Strains}

Clinical isolates from patients with infections of Candida albicans (1581), Candida parapsilosis $(27,470)$, Candida glabrata $(3808)$, and Candida guillermondii $(12,146)$ from the Oslo University Hospital strain collection were used for the experiments. C. albicans and C. glabrata strains were included in all the experiments, while C. parapsilosis was used in biofilm formation experiments and C. guillermondii was also included in the study on the preformed biofilms. The two strains C. albicans and C. glabrata were chosen because they represent susceptibility and resistance to Flu and Mcz.

\subsection{Candida Inocula}

Candida strains were grown on Sabouraud agar at $37^{\circ} \mathrm{C}$ for $48 \mathrm{~h}$. Yeast suspensions were prepared in sterile water by touching ten colonies from a culture plate and standardized to $1 \times 10^{7} \mathrm{CFU} \mathrm{mL}{ }^{-1}$ ) using spectrophotometric methods. One milliliter of the fungal suspension was added to $9 \mathrm{~mL}$ of Roswell Park Memorial Institute Medium (RPMI, Merck KGaA, Darmstadt, Germany).

\subsection{Biofilm Formation}

Biofilm production was based on the method standardized by Chandra et al. (2001) with some modifications [5]. Briefly, yeast inocula were seeded into the wells $\left(1 \mathrm{~mL}\right.$ well $\left.{ }^{-1}\right)$ of pre-sterilized, polystyrene, flat-bottom, tissue culture-treated, 24-well microtiter plates with a $1.9 \mathrm{~cm}^{2}$ well surface (Corning Incorporated, Corning, NY, USA). Non-adherent cells were removed by washing the wells three times in sterile PBS, and RPMI medium was added $\left(1 \mathrm{~mL}\right.$ well $\left.{ }^{-1}\right)$. Microtiter plates were then incubated for 3,24 , and $48 \mathrm{~h}$ at $37^{\circ} \mathrm{C}$.

\subsection{Candida Cell Enumeration in Biofilms}

Biofilm disruption was made by trypsinization as described next. Biofilms were incubated at $37^{\circ} \mathrm{C}$ with $200 \mu \mathrm{L}$ well ${ }^{-1}$ of Trypsin-EDTA solution $(0.05 \%$ trypsin, $0.02 \%$ EDTA) for $3 \mathrm{~min}$. Incubation of yeasts with the Trypsin-EDTA solution did not affect the viability of the yeasts. After incubation, $800 \mu \mathrm{L}$ well ${ }^{-1}$ of RPMI was added and biofilms were disrupted by scraping. The content of each well was then transferred to an Eppendorf tube and vortexed vigorously for $30 \mathrm{~s}$. Tubes were centrifuged at $5000 \mathrm{rpm}$ for $10 \mathrm{~min}$ and washed three times in PBS. Yeasts were enumerated by serial dilution and seeding in Sabouraud agar.

\subsection{Metabolic Activity Determination}

After biofilm formation, the medium was aspirated, and non-adherent cells were removed by washing the wells three times in sterile PBS. Afterward, $1 \mathrm{~mL}$ of PBS, $10 \mu \mathrm{L}$ menadione solution (1 $\mathrm{mM}$ in DMSO), and $12.5 \mu \mathrm{L}$ 2,3-bis(2-methoxy-4-nitro-5-sulfophenyl)-5[(phenyl amino) carbonyl]-2H-tetrazolium hydroxide (XTT) were added to each well [25]. Plates were then incubated at $37^{\circ} \mathrm{C}$ for $5 \mathrm{~h}$. After incubation, the content of the wells was transferred into tubes and centrifuged ( $5 \mathrm{~min}, 5000 \mathrm{rpm})$. XTT formazan in the supernatant was determined spectrophotometrically $(492 \mathrm{~nm})$.

\subsection{Effect of C32 and Flu on Preformed Biofilms}

Working concentrations of C32 and Flu were prepared in RPMI using a 20 or $12.8 \mathrm{mg} \mathrm{mL}^{-1}$ stock solution, respectively. Candida biofilms, obtained as described above, were washed three times with sterile PBS to remove non-adherent cells. C32 or Flu in RPMI, at different concentrations, were added to the wells $\left(1 \mathrm{~mL} \mathrm{well}^{-1}\right)$. The plates were then incubated for $24 \mathrm{~h}$ at $37^{\circ} \mathrm{C}$. The effect of $\mathrm{C} 32$ and Flu on preformed biofilms was estimated by plate counting, as previously described.

\subsection{Effect of $C 32$ and $C A$ on Biofilm Formation}

Yeast inocula were prepared in sterile water as previously described. One milliliter of the suspension was diluted into $9 \mathrm{~mL}$ of $\mathrm{C} 32$ or commercial antifungals (CA) in RPMI at the 
appropriate concentration and then added to the microtiter wells $\left(1 \mathrm{~mL}\right.$ well $\left.{ }^{-1}\right)$. Microtiter plates were incubated for $48 \mathrm{~h}$ at $37^{\circ} \mathrm{C}$. Candida biofilm enumeration was performed as described above after 3,24 , and $48 \mathrm{~h}$ of incubation. Concentrations were selected based on previous studies performed by our group on planktonic C. albicans and C. glabrata cells. The sub-inhibitory concentrations used in the C. glabrata experiments were 5000, 32, and $6.25 \mu \mathrm{g} \mathrm{mL}^{-1}$ for $\mathrm{C} 32$, Flu, and Mcz, respectively, and in the C. albicans experiments 5000, 0.12 , and $16 \mu \mathrm{g} \mathrm{mL} \mathrm{m}^{-1}$, respectively.

\subsection{Synergy}

Ranges of minimal detaching concentrations (MDC) for each antifungal were assessed. MDC was the lowest drug concentration that reduced $\geq 1 \log$ the biofilm counts after $24 \mathrm{~h}$ of incubation at $37^{\circ} \mathrm{C}$. Synergy tests were performed in duplicate using combinations of C32 and Flu or Mcz. Positive growth controls were performed in wells not containing antifungals. Minimal detaching concentration in combination (MDCC) was the lowest concentration of the antifungal when used in combination, which reduced $\geq 1 \log$ yeast attachment after $24 \mathrm{~h}$ of incubation at $37^{\circ} \mathrm{C}$. Fractional detaching concentration (FDC) index was the MDCC of each drug divided by the MDC. FDC summation ( $\sum F D C$ ) of each antifungal combination was calculated for every strain tested. Summation values were interpreted as follows: $\leq 0.5$, synergy (S), $>0.5$ and $\leq 4$ : indifference (I), $>4$ : antagonism (A).

\subsection{Statistical Analysis of Data}

Experiments were done at least in duplicate. Experimental data were analyzed using Minitab version 14.1 (Minitab 14, State College, PA, USA). Student's $t$-tests were performed to identify differences between samples. Differences were significant when $p \leq 0.05$. Tukey's range test was used to assess differences between pairs of means.

\section{Results}

\subsection{Candida Biofilm Formation}

Biofilm formation ability was studied for $72 \mathrm{~h}$ on C. albicans, C. glabrata, C. parasilopsis, and C. guillermondii (Figure 1).

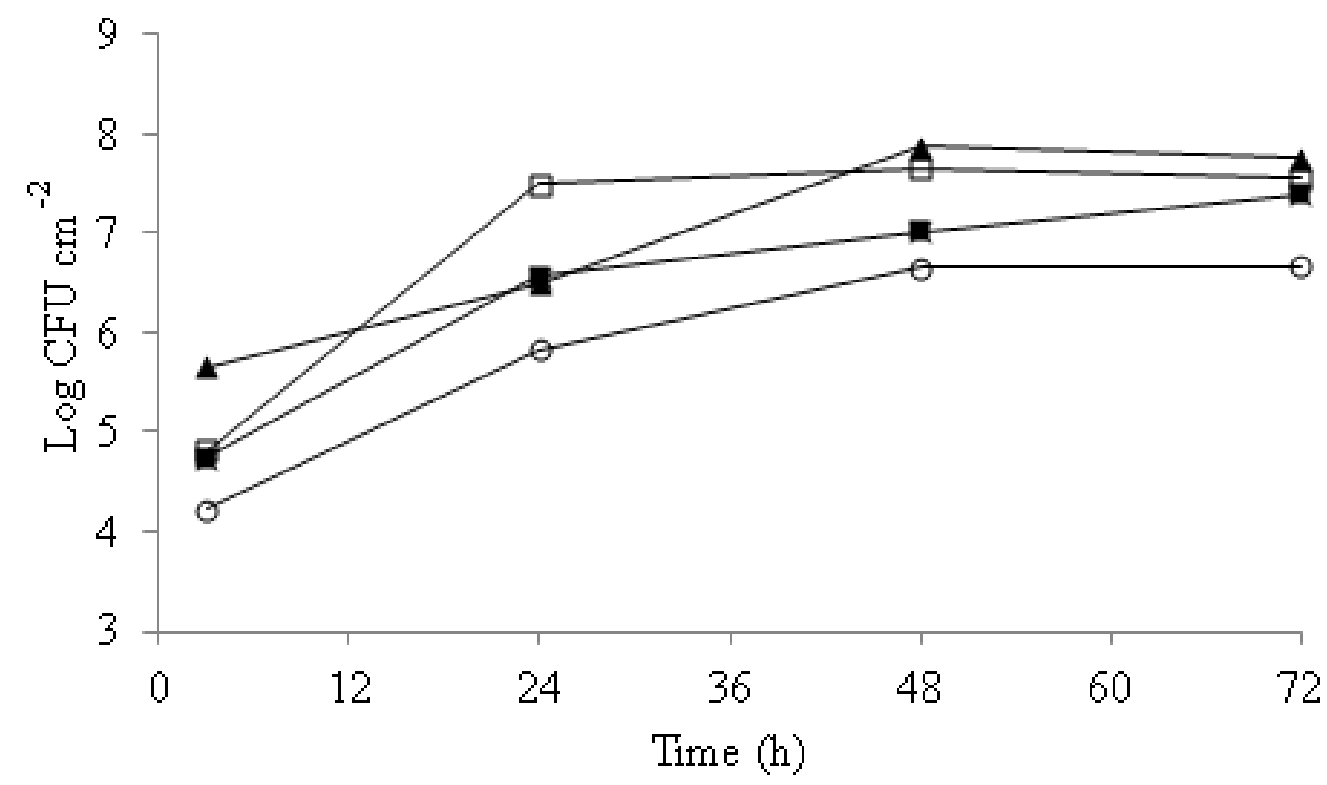

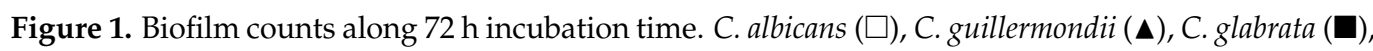
C. parasilopsis $(\bigcirc)$. Experiments were performed in duplicate and the displayed results are from a representative experiment. 
Differences in attachment were observed among strains along the incubation time. C. guillermondii was the strain with the highest initial attachment to the wells, with 5.7 Log CFU cm ${ }^{-2}$, followed by C. albicans and C. glabrata, both with $4.8 \mathrm{Log} \mathrm{CFU} \mathrm{cm}{ }^{-2}$, and 4.1 Log CFU cm ${ }^{-2}$ in the case of C. parasilopsis. After $24 \mathrm{~h}$ of incubation, significant increases in the Candida spp counts were recorded with populations of $7.6 \mathrm{Log} \mathrm{CFU} \mathrm{cm}{ }^{-2}$ for C. albicans, $6.5 \mathrm{Log}$ CFU cm${ }^{-2}$ for C. guillermondii, and $5.8 \mathrm{Log}$ CFU cm$~^{-2}$ for C. parasilopsis. Between 48 and $72 \mathrm{~h}$ of incubation, the biofilm yeast counts did not change significantly $(p>0.05)$.

\subsection{Effect of C32 and CA on Preformed Candida Biofilms}

The potential of C32 to be used for detached preformed yeast biofilms was studied on C. albicans, C. glabrata, and C. guillermondii (Figure 2) on three different biofilm developmental phases: early (3 h), intermediate $(24 \mathrm{~h})$, and mature $(48 \mathrm{~h})$.
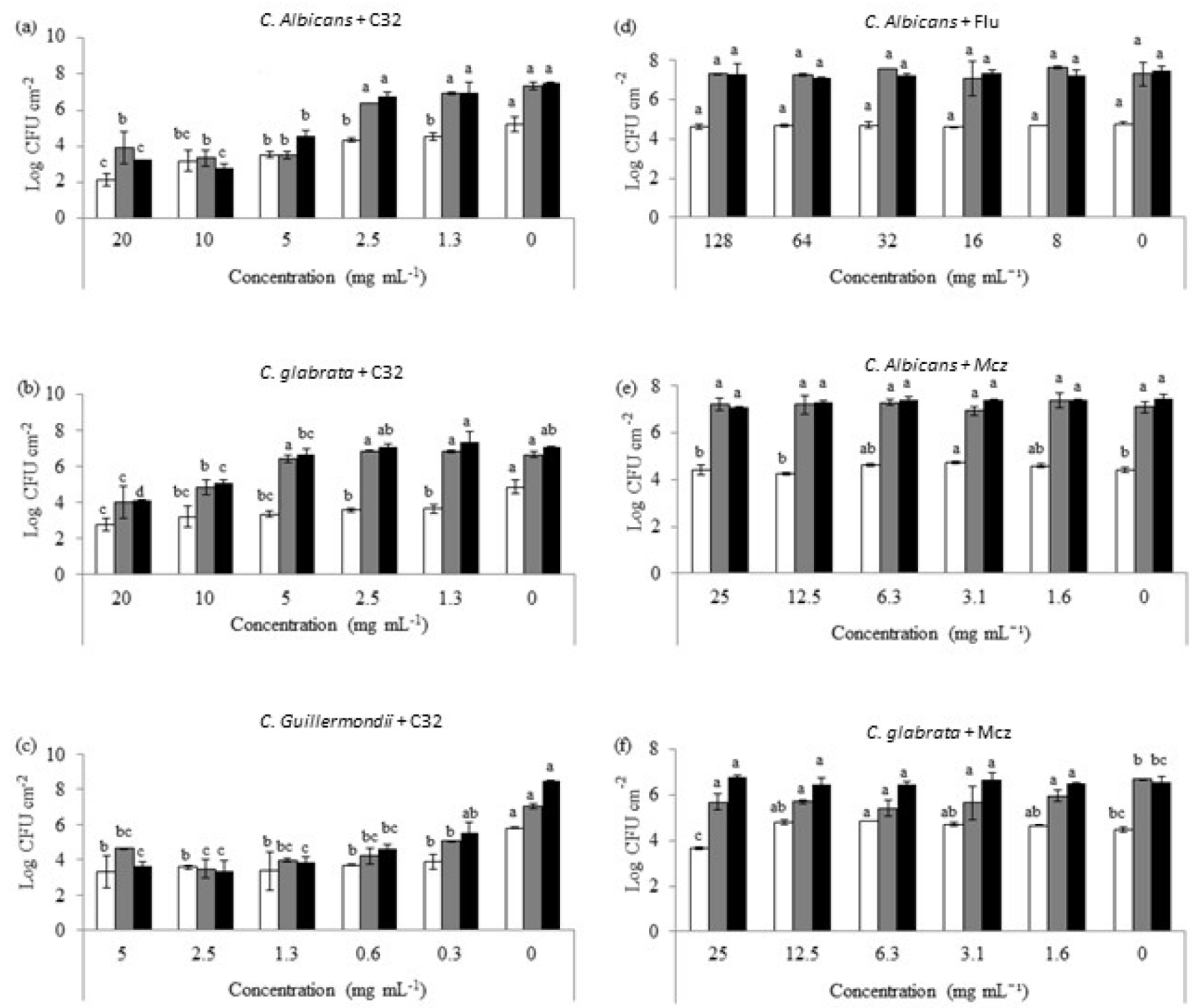

Figure 2. Candida cell counts of early ( $3 \mathrm{~h}$, white), intermediate ( $24 \mathrm{~h}$, grey), and mature ( $48 \mathrm{~h}$, black) biofilms exposed to different concentrations of C32 (C. albicans (a), C. glabrata (b), C. guillermondii (c)) and antifungals (C. albicans and Flu $0.12 \mu \mathrm{g} \mathrm{mL} \mathrm{m}^{-1}$ (d), C. albicans and Mcz $16 \mu \mathrm{g} \mathrm{mL}{ }^{-1}$ (e), C. glabrata and $\left.6.25 \mu \mathrm{g} \mathrm{mL}^{-1} \mathrm{Mcz}(\mathbf{f})\right)$. Bars with the same color and different letters were statistically different $(p \leq 0.05)$. Experiments were performed in triplicate and the results are displayed as the mean of each individual experiment with the calculated standard deviation shown as error bars. 
A concentration-dependent effect on the ability of $\mathrm{C} 32$ to reduce biofilm yeast counts was observed. In the case of $C$. albicans, a decrease $(p>0.05)$ in the counts on early biofilms ( $4.55 \mathrm{Log}$ CFU cm${ }^{-2}$ ) when in the presence of $1.3 \mathrm{mg} \mathrm{mL}^{-1}$ of C32 compared to the control $\left(5.20 \log \mathrm{CFU} \mathrm{cm}{ }^{-2}\right)$ was observed. In addition, there was a significant reduction $(p>0.05)$ in the biofilm-forming yeast counts after 24 and $48 \mathrm{~h}$ of incubation with C32 (3.49 and $4.58 \log$ CFU cm$~_{-2}$, respectively) at $5 \mathrm{mg} \mathrm{mL}^{-1}$ when compared to the control (7.34 and $7.48 \log \mathrm{CFU} \mathrm{cm} \mathrm{c}^{-2}$, respectively). Similarly, a significant reduction $(p>0.05)$ in the counts (3.64 $\log$ CFU cm ${ }^{-2}$ ) was obtained for C. glabrata after $3 \mathrm{~h}$ of incubation with $1.3 \mathrm{mg} \mathrm{mL}^{-1}$ C32 compared to the control (4.88 Log CFU cm${ }^{-2}$ ). After $24 \mathrm{~h}$ of incubation, significant reductions $(p>0.05)$ were obtained for concentrations of 10 and $20 \mathrm{mg} \mathrm{mL}^{-1} \mathrm{C} 32$ (4.85 and $4.02 \mathrm{Log}$ CFU cm$~^{-2}$, respectively) compared to the control $\left(6.65 \mathrm{Log}\right.$ CFU cm$\left.{ }^{-2}\right)$. Likewise, after $48 \mathrm{~h}$ of incubation, reductions ( $p>0.05$ ) were detected for concentrations of $5 \mathrm{mg} \mathrm{mL}^{-1}$ or higher when compared to the control (6.69 and 7.07 $\mathrm{Log} C \mathrm{CFU} \mathrm{cm}{ }^{-2}$, respectively). In the case of $C$. guillermondii, biofilms exposed to $0.3 \mathrm{mg} \mathrm{mL}^{-1}$ of $\mathrm{C} 32$ showed a significant reduction $(p>0.05)$ compared to the control after $3 \mathrm{~h}\left(3.89\right.$ and 5.81Log CFU cm$\left.{ }^{-2}\right)$ and $24 \mathrm{~h}$ of incubation (5.06 and 7.04 $\mathrm{Log} \mathrm{CFU} \mathrm{cm}{ }^{-2}$ ). After $48 \mathrm{~h}$ of incubation, concentrations of $0.6 \mathrm{mg} \mathrm{mL}^{-1}$ significantly $(p>0.05)$ decreased the counts from 8.48 to $4.60 \log \mathrm{CFU} \mathrm{cm}{ }^{-2}$.

Additionally, the effect of Flu and Mcz on preformed Candida biofilms was studied (Figure 2). Flu at the concentrations tested did not show any significant $(p \leq 0.05)$ effect on C. albicans biofilms. Flu at concentrations $\geq 32 \mu \mathrm{g} \mathrm{mL} \mathrm{m}^{-1}$ significantly $(p \leq 0.05)$ reduced C. albicans counts on early biofilms. However, it did not affect the intermediate or mature biofilms. The highest concentration of Mcz tested $\left(25 \mu \mathrm{g} \mathrm{mL}^{-1}\right)$ significantly $(p \leq 0.05)$ reduced $3 \mathrm{~h}$ of old C. glabrata biofilms. However, it did not show any effect on 24 or $48 \mathrm{~h}$ old biofilms.

\subsection{Effect of C32 on the Metabolic Activity of Candida Biofilms}

A XTT assay was performed, and the absorbance of formed formazan product was determined to measure the metabolic activity of C. albicans and C. guillermondii on $24 \mathrm{~h}$-old biofilms in the presence and absence of C32 (Figure 3).

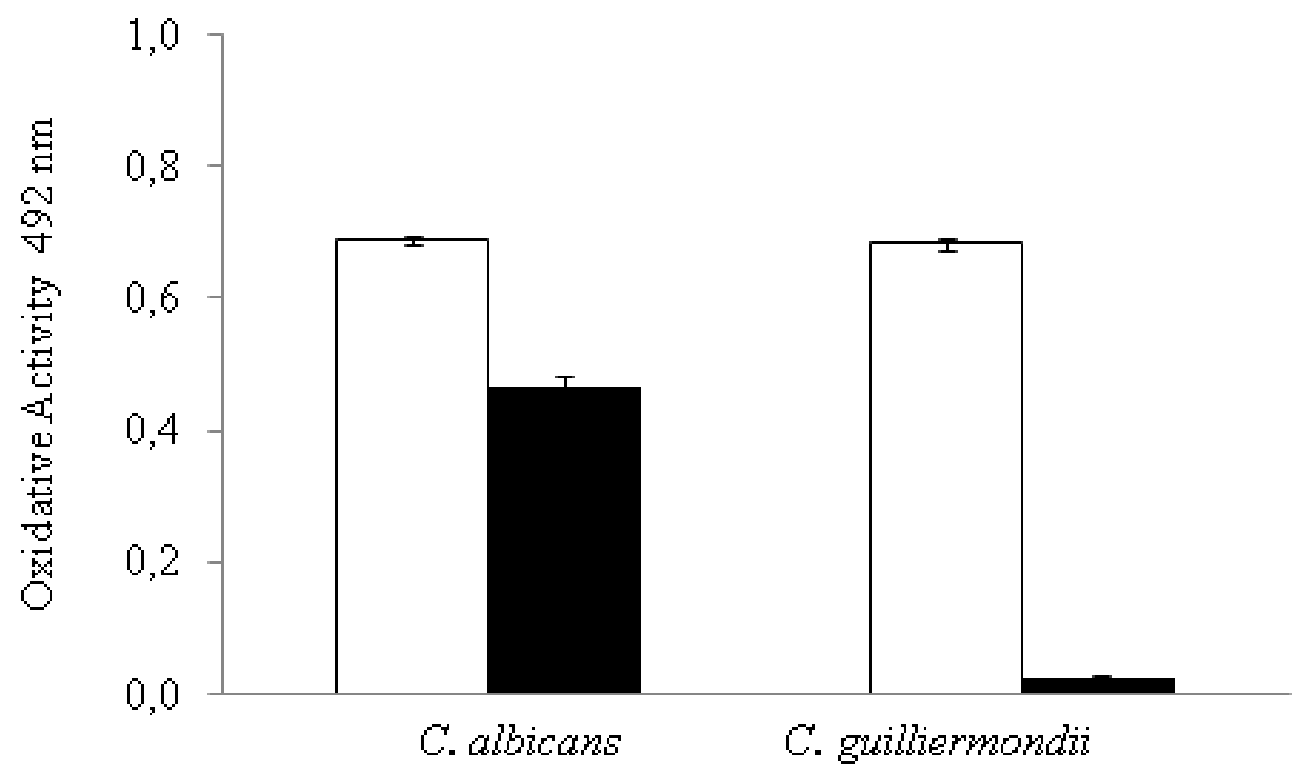

Figure 3. Effect of C32 (black bars) on the metabolic activity of C. albicans and C. guillermondii (white bars) intermediate biofilms as measured by the absorbance of formed formazan as detailed by Hawser et al. [25], the figure is created in this work. Observed effects were statistically different from the control $(p \leq 0.05)$. Experiments were performed in triplicate and the results are displayed as the mean of each individual experiment with the calculated standard deviation shown as error bars. 
Both strains showed a significant decrease in their metabolic activity when treated with C32 compared to the control. However, the decrease was significantly $(p \leq 0.05)$ higher in C. guillermondii ( 0.68 to 0.02 oxidative activity) than in C. albicans biofilms ( 0.69 to 0.46 oxidative activity).

\subsection{Effect of $\mathrm{C} 32$ on the Formation of Candida Biofilms}

The effect of C32 and CA on C. albicans and C. glabrata biofilm formation was studied (Figure 4).

(a)

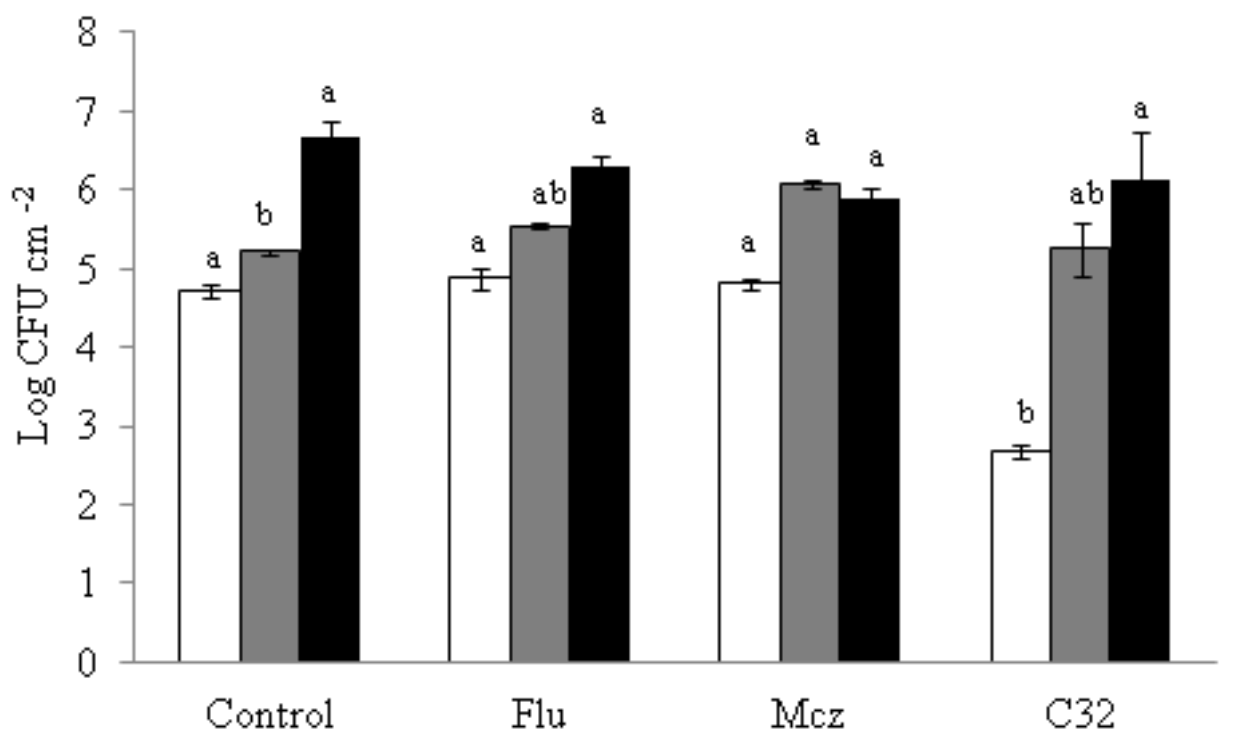

(b)

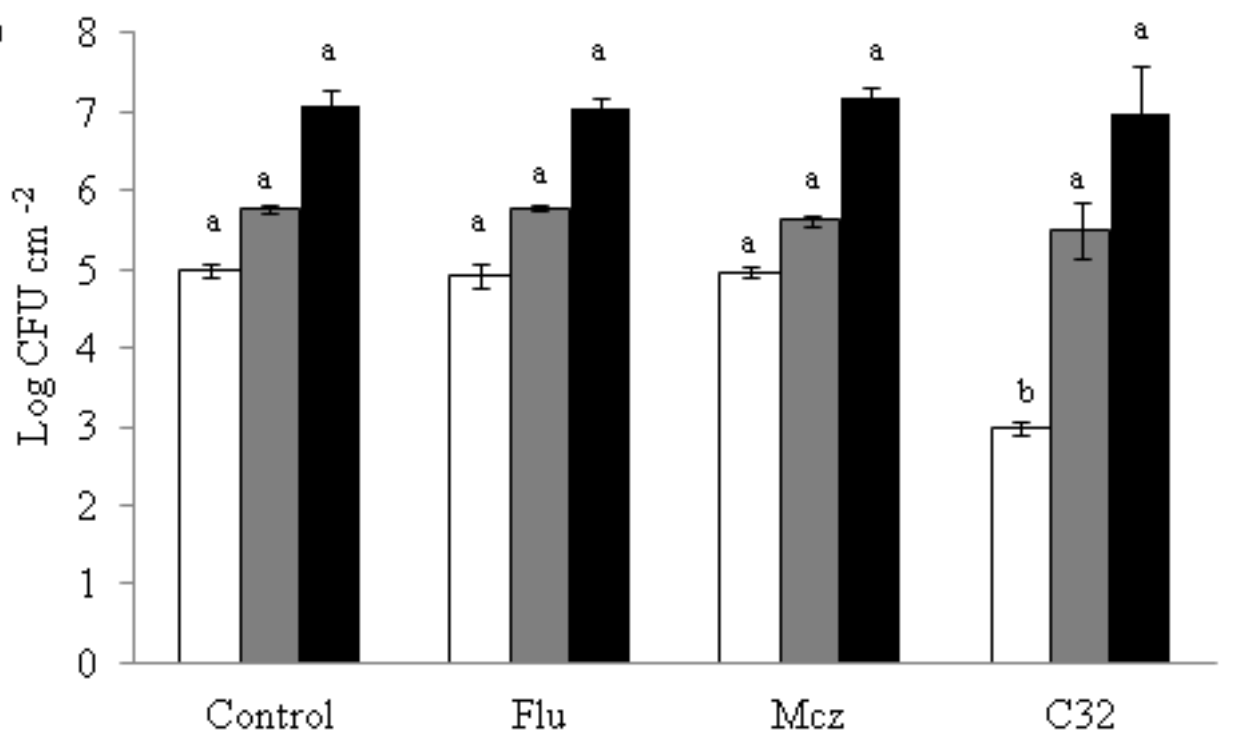

Figure 4. Effect of C32, Flu and Mcz on the formation of C. albicans (a) and C. glabrata (b) biofilms after $3 \mathrm{~h}$ in accordance with the protocol described by White et al. [26]. The figure is created in this work, $24 \mathrm{~h}$ (grey), and $48 \mathrm{~h}$ (black) of incubation. Bars with same color and different letters are statistically different $(p \leq 0.05)$. The sub-inhibitory concentrations used in the C. glabrata experiments were 5000, 32, and $6.25 \mu \mathrm{g} \mathrm{mL}^{-1}$ for C32, Flu, and Mcz, respectively, and in the C. albicans experiments 5000, 0.12 , and $16 \mu \mathrm{g} \mathrm{mL}^{-1}$, respectively. Experiments were performed in triplicate and the results are displayed as the mean of each individual experiment with the calculated standard deviation shown as error bars. 
On both Candida strains, samples exposed to C32 showed a significant $(p \leq 0.05)$ lower attachment to the well surfaces ( $2.67 \log$ CFU cm${ }^{-2}$ for C. albicans and $2.99 \log$ CFU cm ${ }^{-2}$ for C. glabrata) at $3 \mathrm{~h}$ of incubation than the controls ( $4.72 \log \mathrm{CFU} \mathrm{cm}{ }^{-2}$ for C. albicans and $4.98 \log \mathrm{CFU} \mathrm{\textrm {cm } ^ { - 2 }}$ for C. glabrata). This lower attachment effect was not detected when Flu or Mcz were used not combined with CHOS. At 24 and $48 \mathrm{~h}$, no differences $(p>0.05)$ in yeast attachment were observed compared to the control for any of the compounds tested.

\subsection{Combined Antifungal Effect of C32 and CA on Preformed Candida Biofilms}

The combined effect of C32 and Flu or Mcz was studied on C. albicans and C. glabrata biofilms to detect possible synergistic effects (Table 1). MDC of C32 and of the antifungals were reduced when used in combination, suggesting a synergistic effect. In the case of $C$. albicans, Flu MDC on early biofilms decreased from 32 to $8 \mu \mathrm{g} \mathrm{mL}^{-1}$ when in the presence of C32, while C32 MDC was reduced from 5000 to $625 \mu \mathrm{g} \mathrm{mL}-1$ when used in combination with Flu.

Table 1. Combined effect of C32 and CA on the growth of Candida biofilms. MDC: minimum detaching concentration (concentrations in $\mu \mathrm{g} \mathrm{mL}^{-1}$ ), CA: commercial antifungals, Flu: fluconazole, Mcz: miconazole, S: synergy, I: indifference.

\begin{tabular}{|c|c|c|c|c|c|c|c|}
\hline & CA & Time (h) & CA MDC Alone & $\begin{array}{c}\text { CA MDC in } \\
\text { Presence of C } 32\end{array}$ & $\begin{array}{l}\text { C32 MDC } \\
\text { Alone }\end{array}$ & $\begin{array}{c}\text { C32 MDC in } \\
\text { Presence of CA }\end{array}$ & $\begin{array}{l}\text { Detection of } \\
\text { S or I }\end{array}$ \\
\hline \multirow{6}{*}{ C. albicans } & \multirow{3}{*}{ Flu } & 3 & $>32.00$ & 8.00 & 5000.00 & 625.00 & $S$ \\
\hline & & 24 & $>32.00$ & 8.00 & 2500.00 & 625.00 & $S$ \\
\hline & & 48 & $>32.00$ & 8.00 & 2500.00 & 625.00 & $S$ \\
\hline & \multirow{3}{*}{ Mcz } & 3 & $>25.00$ & 6.25 & 5000.00 & 625.00 & $S$ \\
\hline & & 24 & $>25.00$ & 6.25 & 2500.00 & 625.00 & $S$ \\
\hline & & 48 & $>25.00$ & 6.25 & 2500.00 & 625.00 & S \\
\hline \multirow{3}{*}{ C. glabrata } & \multirow{3}{*}{ Mcz } & 3 & $>25.00$ & 6.25 & $>10,000.00$ & 625.00 & $S$ \\
\hline & & 24 & $>25.00$ & 6.25 & $10,000.00$ & 625.00 & $S$ \\
\hline & & 48 & $>25.00$ & 12.50 & $10,000.00$ & 1250.00 & I \\
\hline
\end{tabular}

\section{Discussion}

Pathogenic fungi in the genus Candida cause superficial biofilms and biofilms in serious systemic disease. Candida spp are involved in the formation of biofilms on implanted devices. The development of pathogenic biofilms remains a major problem with severe clinical implications and therapeutic challenges of antifungal resistance. In this preliminary work, the activity of the well-characterized CHOS C 32 on Candida biofilms were studied. It was observed that C32 reduced biofilm formation in early developmental stages. Additionally, a reduction in the number of viable cells present in Candida preformed biofilms in the presence of C32 was detected, especially in intermediate and mature biofilms. In contrast, it was observed that the azoles Flu and Mcz reduced the number of viable cells in early biofilms, but not in intermediate or mature ones. Concerning these results, in a previous study, Chandra et al. [5] reported that antifungal resistance of biofilm-grown cells increased with the biofilm phase, with mature ones the most resistant to different antifungals including amphotericin B, fluconazole, nystatin, and chlorhexidine.

Previously, chitosan has been tested against biofilms. For instance, using the semi quantitative XXT test, Silva-Dias et al. (2014) [27] found that a low molecular weight chitosan hydrogel impairs biofilm formation and disorganizes preformed ones in vitro and in vivo. Additionally, Martinez et al. [28] showed that chitosan significantly reduced the cell viability and the metabolic activity of Cryptococcus neoformans preformed mature biofilms. Using confocal and scanning electron microscopy, the authors also demonstrated that chitosan penetrates biofilms and damages fungal cells. Similarly, Carlson et al. [29] observed reductions in biofilms where viable cell numbers ranged from $95 \%$ to $99 \%$ on the bacteria Staphylococcus epidermidis, Staphylococcus aureus, Klebsiella pneumoniae, Pseudomonas aeruginosa, and on the yeast Candida albicans on chitosan-coated surfaces. In the 
case of C. albicans, chitosan-coated surfaces reduced surface-associated growth in more than $3 \log$ CFU cm $\mathrm{cm}^{-2}$ compared to the control surface. Additionally, Tan et al. [30] studied the effect of gentamicin, chitosan, and a chitosan derivative (hydroxypropyltrimethyl ammonium chloride chitosan, HACC) on the formation of Staphylococcus spp. biofilms on the surface of bone cements. The group observed that, in contrast to chitosan, HACC prevents bacterial biofilm formation and downregulates virulence-associated gene expression of antibiotic-resistant bacteria. Gentamicin, on the other hand, decreased the number of viable methicillin-resistant Staphylococcus strains, but its ability to inhibit biofilm formation was lower than that of HACC.

Chitosan and its derivatives have, due to their antifungal activity, potential to be used for treating yeast infections in humans [1]. Synergistic drug combinations and combinations of CHOS and antifungals have been shown to be effective against planktonic Candida and appear to be potential therapeutic interventions to treat or prevent biofilms [31].

In this study, a reduction in the MDC of both C32 and Flu/Mcz, when used in combination on preformed yeast biofilms, was observed (Figure 2). This finding suggests that the mechanisms of action is a synergistic (Table 1), concentration-dependent reduction in the number of viable cells present in C. albicans, C. glabrata, and C. guillermondii preformed biofilms in the presence of C32, especially on intermediate and mature biofilms. A significant decrease in the metabolic activity of Candida biofilms treated with C32 was also observed (Figure 3). The azole antifungals fluconazole (Flu) and miconazole (Mcz) decreased the number of viable cells in preformed early biofilms, but not in intermediate or mature biofilms. Contrary to Flu or Mcz, C32 also reduced the formation of new biofilms. Similar results have been reported by Chauhan et al. [32], who studied the synergistic activity of a chelator (EDTA) and an antibiotic drug. The group showed that a single-dose of EDTA-gentamicin fully eliminated preformed S. aureus catheter-associated biofilms in rats. However, EDTA and gentamicin alone were not completely effective against the biofilms. It is known that metal cations are essential for microbial adherence, biofilm formation, and microbial growth. Therefore, metal-binding chelators have the capability of inhibiting biofilm formation by disrupting surface adherence and preventing biofilm production [33]. Similarly to EDTA, chitosan is an important metal-chelator [34], which could explain its detrimental activity on biofilm formation and the synergy observed with antifungal drugs. Using C32 or other non-antifungal drugs in combination with CA will be a way to overcome antifungal resistance in biofilm infections. The mechanism of action studied using confocal imaging showed that C32 adsorbs to the cell surface, with subsequent cell disruption and accumulation of C32 in the cytoplasm [2]. In addition, the use of such combination therapy will reduce the amounts of antifungals used and thus decrease the development of antifungal resistance.

\section{Conclusions}

We conclude that C32 effectively reduced Candida biofilms and combined use with the antifungal drugs fluconazole and miconazole had a synergistic effect on Candida biofilms. The use of combination therapy with C32 and fluconazole and miconazole will reduce antifungal use and decrease antifungal resistance compared to combination therapy using monotherapy with antifungal drugs. Considering these results, we believe that C32 deserves further exploration for use in clinical practice for the treatment of Candida biofilm infections.

Author Contributions: Conceptualization, M.G., P.G., S.B.L. and M.S.; Formal analysis: M.G.; Investigation: M.G. and S.B.L.; Supervision: P.G. and M.S.; Writing—original draft: M.G.; Writingreview and editing: P.G. and M.S. All authors have read and agreed to the published version of the manuscript.

Funding: This work was supported by the Research Council of Norway through grant 226280 to MS. The funder had no role in study design, data collection and analysis, decision to publish, or preparation of the manuscript. 
Acknowledgments: This work was supported by the Research Council of Norway through grant 226280 to MS.

Conflicts of Interest: The authors declare no conflict of interest.

\section{References}

1. Colombo, A.L.; Júnior, J.N.D.A.; Guinea, J. Emerging multidrug-resistant Candida species. Curr. Opin. Infect. Dis. 2017, 30, 528-538. [CrossRef] [PubMed]

2. Ganan, M.; Lorentzen, S.B.; Agger, J.W.; Heyward, C.A.; Bakke, O.; Knutsen, S.H.; Aam, B.B.; Eijsink, V.G.H.; Gaustad, P.; Sørlie, M. Antifungal activity of well-defined chito-oligosaccharide preparations against medically relevant yeasts. PLoS ONE 2019,14 , e0210208. [CrossRef] [PubMed]

3. Ganan, M.; Lorentzen, S.B.; Aam, B.B.; Eijsink, V.G.H.; Gaustad, P.; Sørlie, M. Antibiotic saving effect of combination therapy through synergistic interactions between well-characterized chito-oligosaccharides and commercial antifungals against medically relevant yeasts. PLoS ONE 2019, 14, e0227098. [CrossRef]

4. Rahman, H.; Shovan, L.R.; Hjeljord, L.G.; Aam, B.B.; Eijsink, V.G.H.; Sørlie, M.; Tronsmo, A. Inhibition of Fungal Plant Pathogens by Synergistic Action of Chito-Oligosaccharides and Commercially Available Fungicides. PLoS ONE 2014, 9, e93192. [CrossRef]

5. Chandra, J.; Kuhn, D.M.; Mukherjee, P.K.; Hoyer, L.L.; McCormick, T.; Ghannoum, M.A. Biofilm Formation by the Fungal Pathogen Candida Albicans: Development, Architecture, and Drug Resistance. J. Bacteriol. 2001, 183, 5385-5394. [CrossRef] [PubMed]

6. Raad, I.; Hanna, H.; Maki, D. Intravascular Catheter-Related Infections: Advances in Diagnosis, Prevention, and Management. Lancet Infect. Dis. 2007, 7, 645-657. [CrossRef]

7. Mermel, L.; Allon, M.; Bouza, E.; Craven, D.; Flynn, P.; O'Grady, N.; Raad, I.; Rijnders, B.; Sherertz, R.; Warren, D. Clinical Practice Guidelines for the Diagnosis and Management of Intravascular Catheter-Related Infection: 2009 Update by the Infectious Diseases Society of America. Clin. Infect. Dis. 2009, 49, 1-45. [CrossRef]

8. Harriott, M.M.; Lilly, E.A.; Rodriguez, T.E.; Fidel, P.L.; Noverr, M. Candida albicans forms biofilms on the vaginal mucosa. Microbiology 2010, 156, 3635-3644. [CrossRef]

9. GGanguly, S.; Mitchell, A.P. Mucosal biofilms of Candida albicans. Curr. Opin. Microbiol. 2011, 14, 380-385. [CrossRef]

10. Ramage, G.; Tomsett, K.; Wickes, B.L.; López-Ribot, J.L.; Redding, S.W. Denture Stomatitis: A Role for Candida Biofilms. Oral Surg. Oral Med. Oral Pathol. Oral Radiol. Endodont. 2004, 98, 53-59. [CrossRef] [PubMed]

11. Douglas, L. Candida biofilms and their role in infection. Trends Microbiol. 2003, 11, 30-36. [CrossRef]

12. Kean, T.; Thanou, M. Biodegradation, biodistribution and toxicity of chitosan. Adv. Drug Deliv. Rev. 2010, 62, 3-11. [CrossRef]

13. Kasaai, M.R. Determination of the degree of N-acetylation for chitin and chitosan by various NMR spectroscopy techniques: A review. Carbohydr. Polym. 2010, 79, 801-810. [CrossRef]

14. Knaul, J.Z.; Kasaai, M.R.; Bui, V.T.; Creber, K.A. Characterization of deacetylated chitosan and chitosan molecular weight review. Can. J. Chem. 1998, 76, 1699-1706. [CrossRef]

15. Wang, Q.Z.; Chen, X.G.; Liu, N.; Wang, S.X.; Liu, C.; Meng, X.H. Protonation constants of chitosan with different molecular weight and degree of deacetylation. Carbohydr. Polym. 2006, 65, 194-201. [CrossRef]

16. Atanase, L. Micellar Drug Delivery Systems Based on Natural Biopolymers. Polymers 2021, 13, 477. [CrossRef] [PubMed]

17. Iurciuc-Tincu, C.E.; Atanase, L.I.; Ochiuz, L.; Jérôme, C.; Sol, V.; Martin, P.; Popa, M. Curcumin-Loaded Polysaccharides-Based Complex Particles Obtained by Polyelectrolyte Complexation and Ionic Gelation. I-Particles Obtaining and Characterization. Int. J. Biol. Macromol. 2020, 147, 629-642. [CrossRef] [PubMed]

18. Rata, D.M.; Cadinoiu, A.N.; Atanase, L.I.; Bacaita, S.E.; Mihalache, C.; Daraba, O.-M.; Gherghel, D.; Popa, M. "In vitro" behaviour of aptamer-functionalized polymeric nanocapsules loaded with 5-fluorouracil for targeted therapy. Mater. Sci. Eng. C 2019, $103,109828$. [CrossRef]

19. Aam, B.B.; Heggset, E.B.; Norberg, A.L.; Sørlie, M.; Vårum, K.M.; Eijsink, V.G. Production of Chitooligosaccharides and Their Potential Applications in Medicine. Marr. Drugs 2010, 8, 1482-1517. [CrossRef] [PubMed]

20. Keong, L.C.; Halim, A.S. In Vitro Models in Biocompatibility Assessment for Biomedical-Grade Chitosan Derivatives in Wound Management. Int. J. Mol. Sci. 2009, 10, 1300-1313. [CrossRef]

21. Kong, M.; Chen, X.G.; Xing, K.; Park, H.J. Antimicrobial properties of chitosan and mode of action: A state of the art review. Int. J. Food Microbiol. 2010, 144, 51-63. [CrossRef]

22. Cassone, M.; Otvos, L., Jr. Synergy among Antibacterial Peptides and between Peptides and Small-Molecule Antibiotics. Expert. Rev. Anti Infect. Ther. 2010, 8, 703-716. [CrossRef] [PubMed]

23. Duong, L.; Gross, S.P.; Siryaporn, A. Developing Antimicrobial Synergy with AMPs. Front. Med Technol. 2021, 3, 9. [CrossRef]

24. Rahman, H.; Hjeljord, L.G.; Aam, B.B.; Sørlie, M.; Tronsmo, A. Antifungal effect of chito-oligosaccharides with different degrees of polymerization. Eur. J. Plant Pathol. 2015, 141, 147-158. [CrossRef]

25. Hawser, S.P.; Norris, H.; Jessup, C.J.; Ghannoum, M.A. Comparison of a 2,3-Bis(2-Methoxy-4-Nitro-5-Sulfophenyl)-5[(Phenylamino)Carbonyl]-2h-T Etrazolium Hydroxide (Xtt) Colorimetric Method with the Standardized National Committee for Clinical Laboratory Standards Method of Testing Clinical Yeast Isolates for Susceptibility to Antifungal Agents. J. Clin. Microbiol. 1998, 36, 1450-1452. [PubMed] 
26. White, R.L.; Burgess, D.S.; Manduru, M.; Bosso, J.A. Comparison of Three Different in Vitro Methods of Detecting Synergy: Time-Kill, Checkerboard, and E Test. Antimicrob. Agents Chemother. 1996, 40, 1914-1918. [CrossRef]

27. Silva-Dias, A.; Palmeira-De-Oliveira, A.; Miranda, I.; Branco, J.; Cobrado, L.; Monteiro-Soares, M.; Queiroz, J.; Pina-Vaz, C.; Rodrigues, A.G. Anti-biofilm activity of low-molecular weight chitosan hydrogel against Candida species. Med Microbiol. Immunol. 2014, 203, 25-33. [CrossRef]

28. Martinez, L.R.; Mihu, M.R.; Tar, M.; Cordero, R.J.; Han, G.; Friedman, A.J.; Friedman, J.M.; Nosanchuk, J.D. Demonstration of Antibiofilm and Antifungal Efficacy of Chitosan against Candidal Biofilms, Using an in Vivo Central Venous Catheter Model. J. Infect. Dis. 2010, 201, 1436-1440. [CrossRef]

29. Carlson, R.P.; Taffs, R.; Davison, W.M.; Stewart, P.S. Anti-biofilm properties of chitosan-coated surfaces. J. Biomater. Sci. Polym. Ed. 2008, 19, 1035-1046. [CrossRef]

30. Tan, H.; Peng, Z.; Li, Q.; Xu, X.; Guo, S.; Tang, T. The use of quaternised chitosan-loaded PMMA to inhibit biofilm formation and downregulate the virulence-associated gene expression of antibiotic-resistant staphylococcus. Biomaterials 2012, 33, 365-377. [CrossRef]

31. Uppuluri, P.; Nett, J.; Heitman, J.; Andes, D. Synergistic Effect of Calcineurin Inhibitors and Fluconazole against Candida albicans Biofilms. Antimicrob. Agents Chemother. 2008, 52, 1127-1132. [CrossRef] [PubMed]

32. Chauhan, A.; Lebeaux, D.; Ghigo, J.-M.; Beloin, C. Full and Broad-SpectrumIn VivoEradication of Catheter-Associated Biofilms Using Gentamicin-EDTA Antibiotic Lock Therapy. Antimicrob. Agents Chemother. 2012, 56, 6310-6318. [CrossRef]

33. I Raad, I.; Fang, X.; Keutgen, X.M.; Jiang, Y.; Sherertz, R.; Hachem, R. The role of chelators in preventing biofilm formation and catheter-related bloodstream infections. Curr. Opin. Infect. Dis. 2008, 21, 385-392. [CrossRef] [PubMed]

34. Qin, Y. The chelating properties of chitosan fibers. J. Appl. Polym. Sci. 1993, 49, 727-731. [CrossRef] 